\title{
Vegetative and Floral Chilling Requirements of Four New Kiwi Cultivars of Actinidia chinensis and $A$. deliciosa
}

\author{
Clint Wall ${ }^{1}$, William Dozier ${ }^{2}$, Robert C. Ebel $^{3,7}$ Bryan Wilkins $^{4}$, \\ Floyd Woods ${ }^{5}$, and Wheeler Foshee III $^{6}$ \\ Department of Horticulture, 101 Funchess Hall, Auburn University, AL \\ 36849
}

Additional index words. phenology, growing degree hours, bloom, bud break

\begin{abstract}
Kiwifruit (Actinidia deliciosa A. Chev. and Actinidia chinensis Planch) require winter chilling to complete rest and growing degree hours to grow. This study was conducted to compare the chilling requirement and growing degree hours for budbreak and floral development of two female cultivars of $A$. chinensis, 'Golden Sunshine' and 'Golden Dragon', two female cultivars of $A$. deliciosa, 'AU Fitzgerald' and 'Hayward', and two male cultivars of $A$. deliciosa, 'AU Authur' and 'Matua'. In 2005 and 2006, shoot cuttings were made from dormant 1-year canes at nodes 6 to 20, starting from the basal end of canes and held in cold storage at $4{ }^{\circ} \mathrm{C}$. Cuttings were removed from storage and flowering was forced in a greenhouse maintained at $25^{\circ} \mathrm{C}$. Maximum budbreak was determined to be $700 \mathrm{~h}$ for 'Golden Sunshine', $800 \mathrm{~h}$ for 'Golden Dragon' and 'AU Fitzgerald', and $900 \mathrm{~h}$ for 'Hayward', 'Matua', and 'AU Authur'. Growing degree hour to first budbreak were 9,500 h for 'Golden Dragon' and 15,000 h for 'Golden Sunshine', with the correlation of determination too low for the other cultivars. The high heat requirement for 'Gold Sunshine' would reduce the risk of injury by late spring frosts. Bloom period of both male cultivars overlapped with bloom periods for all cultivars except 'Golden Dragon' for fully mature vines in the field.
\end{abstract}

Actinidia deliciosa A. Chev. and A. chinensis Planch. are dioecious species that have vegetative and compound buds, with flower clusters produced in the leaf axils of the first four to six nodes. Male and female flowers are perfect morphologically. The female flower contains some anthers, but only the stigma is functional, whereas the male vine typically produces 125 to 185 large anthers that surround a small, vestigial stigma (Thorp, 1994). Commercial kiwifruit production requires interplanting female and male plants for sufficient pollination to promote commercial fruit size (Grant et al., 1994).

Kiwi buds enter endodormancy during winter, which requires a minimum number of chilling hours for maximum budbreak and bloom (Lionakis and Schwabe, 1984; Snelgar et al., 1997). Floral uniformity and density in

Received for publication 27 Aug. 2007. Accepted for publication 30 Nov. 2007.

This project was funded in part by the Alabama Agricultural Experiment Station.

${ }^{1}$ Graduate Research Assistant

${ }^{2}$ Professor

${ }^{3}$ Associate Professor. Current address: Southwest Florida Research and Education Center, University of Florida, IFAS, 2686 Hwy 29 N., Immokalee, FL 34142.

${ }^{4}$ Field Research Associate III

${ }^{5}$ Associate Professor

${ }^{6}$ Assistant Professor

${ }^{7}$ To whom reprint requests should be addressed; e-mail rcebel@ufl.edu
Alabama, which has an average winter chilling of 800 to $1200 \mathrm{~h}$. This study was conducted to determine the chilling requirement of 'Golden Sunshine', 'Golden Dragon', and 'AU Fitzgerald'. Two male cultivars, 'AU Authur' (another cultivar that is being released by Auburn University) and 'Matua', were also tested to determine overlap in bloom with the female cultivars. Determining the chilling hours will aid decisions regarding recommendations in planting these cultivars in various climatic regions.

\section{Materials and Methods}

Self-rooted cuttings of 'Hayward', 'AU Fitzgerald', 'Golden Sunshine', 'Golden Dragon', 'Matua' and 'AU Authur' were planted in 1985 at a spacing of $2.4 \times 4.8 \mathrm{~m}$ at the Chilton Area Research and Extension Center in Thorsby, Alabama. The soil was a Bama fine sandy loam (fine sand loam, siliceous, subactive, thermic, Typic Paleudults). The vines received typical commercial culture since planting. Located within 0.1 $\mathrm{km}$ of the experimental site was an electronic weather station that recorded hourly temperatures.

In 2005 and 2006, shoot cuttings were made from dormant 1 -year canes at nodes 6 to 20 , starting from the basal end of canes. Multiple vines for each cultivar were selected and cuttings were pooled by cultivar. The cuttings were placed in water and were immediately transported to Auburn University. The cuttings were held in cold storage at $4{ }^{\circ} \mathrm{C}$.

In 2005, cuttings were made on 19 Jan., after being exposed to 572 chilling hours in the field and were removed after cold storage for a total of $600-950 \mathrm{~h}$, which included chilling hours from the field and cold storage. All chill hours were determined using the Richardson method (Grant et al., 1994; Samish and Levee, 1962). The experiment was conducted as a randomized complete block design with six blocks and one jar per genotype per block. Ten cuttings as subsamples were placed in each jar. The jars were wrapped with aluminum foil to exclude light to the base of the shoot and were filled with water ( $\mathrm{pH} 6.0$ and no fertilizer), which kept the basal end of the cuttings saturated throughout the experiment. The greenhouse was maintained at $25{ }^{\circ} \mathrm{C}$ with ambient relative humidity.

In 2006, the experiment was repeated except that 'Hayward' and 'Matua' were not used in the study. 'Golden Sunshine' and 'Golden Dragon' cuttings were collected earlier in the winter (21 Nov. 2005), when $150 \mathrm{~h}$ of chilling had been received in the field, and 'AU Fitzgerald' and 'AU Authur' cuttings were collected when $458 \mathrm{~h}$ of field chilling had accumulated (16 Dec. 2005). Canes were removed from storage after 150 to $1160 \mathrm{~h}$ and buds were forced as the previous year.

In both years, shoots that emerged from buds were counted daily. Floral buds were also counted, as well as the stage of development of each flower, including full bloom, 
petal fall, and senescence. Data were collected until floral parts stopped developing or had abscised and leaves had begun to appear chlorotic or necrotic.

Data were analyzed using the nonlinear procedure of the Statistical Analysis System (SAS, Cary, NC). Means were derived for each day, and dependent variables were fitted to numbers of chill hours using a Gompertz regression (Lim et al., 1998; Lindén et al., 2000). Development of the curve required a constant that was the asymptote of the function. The constant was found by graphing the data and estimating the asymptote and then testing several values near the asymptote until the highest regression coefficient was found. The regression coefficient was determined by 1-(ESS/CTSS), where ESS was the error sum of squares and CTSS was the corrected total sum of squares. Because the Gompertz function is asymptotic to a maximum, independent variables were determined to receive sufficient chilling at $95 \%$ of the asymptote. Flower counts were used as an indicator of floral chilling requirement and the number of dormant buds that grew was used as an indicator of vegetative chilling requirement. Growing degree hour $(\mathrm{GDH})$ for first budbreak and first flower development were calculated daily using a base temperature of $4.4^{\circ} \mathrm{C}$ and a maximum temperature of $25{ }^{\circ} \mathrm{C}$. GDH was regressed against chilling hours using an inverse function. The regression coefficient was calculated as before. Minimum GDH for first budbreak and first flower development were solved by using the regressions and the corresponding chilling requirement for first budbreak.

\section{Results and Discussion}

Actinidia chinensis: 'Golden Sunshine' and 'Golden Dragon'. Dormant bud rest was completed, as indicated by maximum budbreak, with $700 \mathrm{~h}$ of chilling for 'Golden Sunshine' (Fig. 1). The maximum number of flowers that developed did not reach a maximum for this experiment; nevertheless, the maximum required at least $900 \mathrm{~h}$ of chilling. We estimated the chilling requirement for maximum number of flowers by calculating the chilling hours at $95 \%$ of the y-axis asymptote. The GDH that required the first buds to break was $15,000 \mathrm{~h}$ and the number of GDH required for first flowers to show was $10,600 \mathrm{~h}$.

Dormant bud rest was completed with $800 \mathrm{~h}$ of chilling for 'Golden Dragon' (Fig. 2). The maximum number of flowers that developed reached a maximum at $800 \mathrm{~h}$ of chilling. The GDH that required the first buds to break was $9,500 \mathrm{~h}$ and the number of GDH required for first flowers to show was $10,100 \mathrm{~h}$.

The coefficients of determination were high for all regressions for 'Golden Sunshine' and 'Golden Dragon', with the lowest $\mathrm{R}^{2}=$ $0.66^{*}$. The high coefficients of determination indicate that the method used here to determine chilling and GDH requirements worked well for these two cultivars.
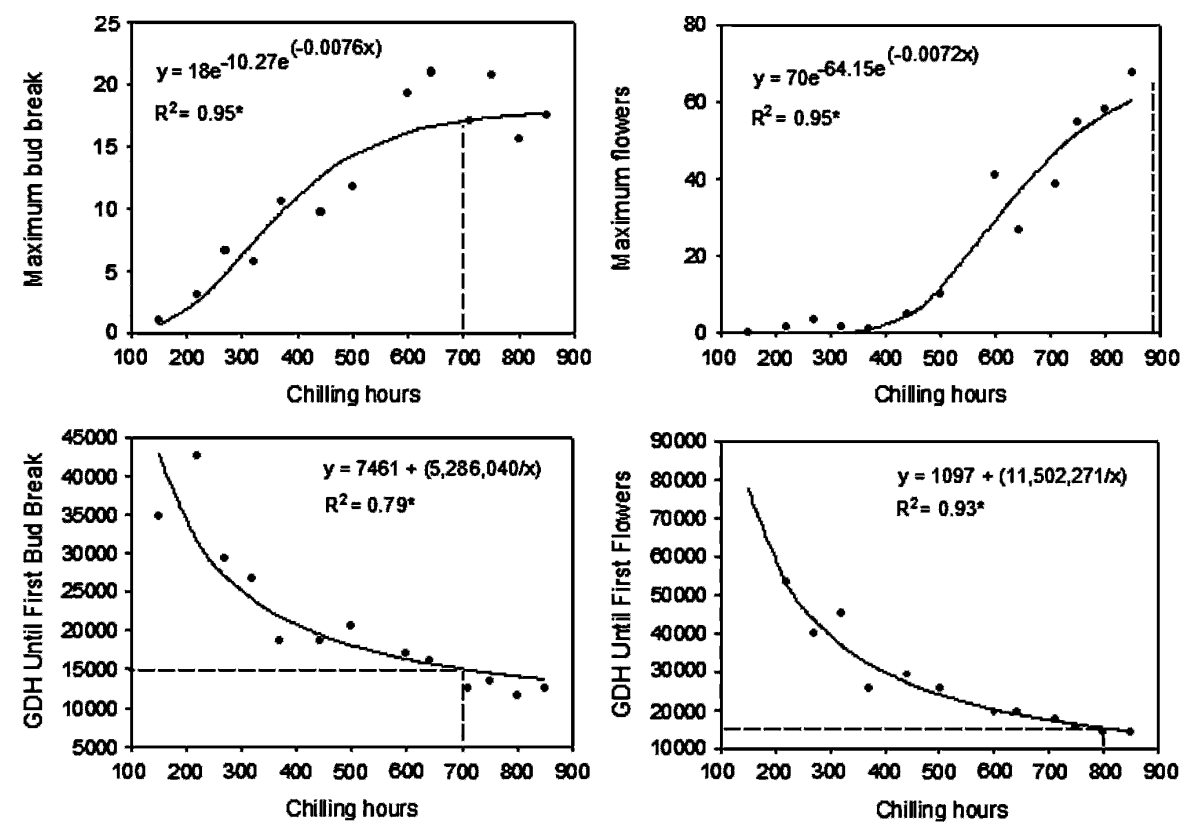

Fig. 1. The effect of chilling hours on maximum budbreak and flowers and the effect of GDH on time until first budbreak and first bloom for 'Golden Sunshine'. The vertical dotted lines in the upper graphs indicate chilling hours for $95 \%$ of the regression asymptote. The horizontal dotted lines in the lower graphs indicate the number of GDH required to reach first budbreak and first bloom at optimum chilling hours. Significance of the regression coefficient was determined at $P<0.05$.
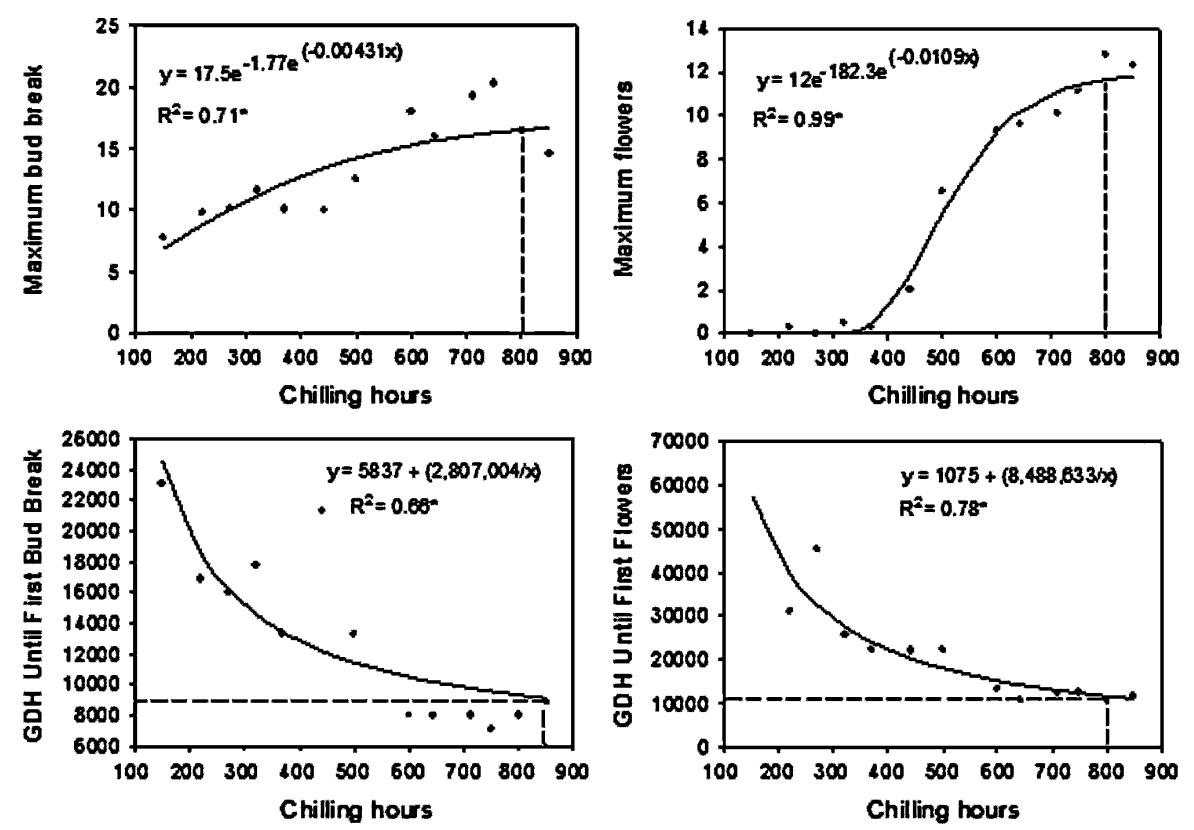

Fig. 2. The effect of chilling hours on maximum budbreak and flowers and the effect of GDH on time until first budbreak and first bloom for 'Golden Dragon'. The vertical dotted lines in the upper graphs indicate chilling hours for $95 \%$ of the regression asymptote. The horizontal dotted lines in the lower graphs indicate the number of GDH required to reach first budbreak and first bloom at optimum chilling hours. Significance of the regression coefficient was determined at $P<0.05$.

Female A. deliciosa: 'Hayward' and 'AU Fitzgerald'. Dormant bud rest was completed with $900 \mathrm{~h}$ of chilling for 'Hayward' (Fig. 3). No flowers developed for this cultivar in this experiment. The failure to produce flowers indicates that its chilling requirement exceeds $950 \mathrm{~h}$, which agrees with a previous study (Caldwell, 1989). The GDH to first budbreak could not be estimated from this study because of a low regression coefficient $\left(\mathrm{R}^{2}=0.03^{\mathrm{ns}}\right)$.
Dormant bud rest was completed with an estimated $800 \mathrm{~h}$ of chilling for 'AU Fitzgerald' (Fig. 4), however, the regression coefficient was low even though it was statistically significant $\left(\mathrm{R}^{2}=0.38^{*}\right)$. The maximum number of flowers that developed were estimated to occur at $1100 \mathrm{~h}$ of chilling, although the low regression coefficient $\left(\mathrm{R}^{2}=0.50 *\right)$ and lack of a clear maximum makes the estimate uncertain. Furthermore, this cultivar has performed well on the coast of the Gulf of 

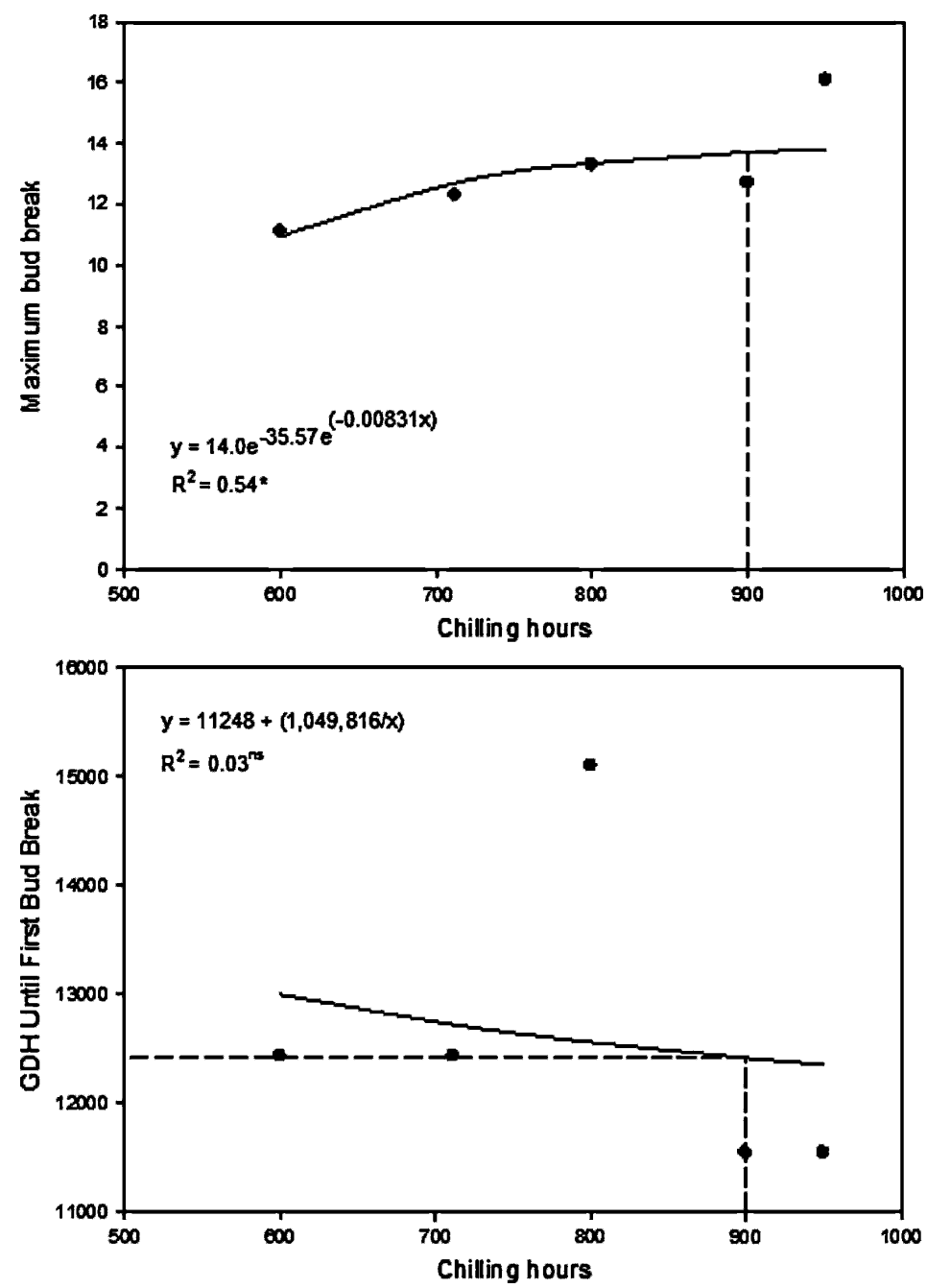

Fig. 3. The effect of chilling hours on maximum budbreak and the effect of GDH on time until first budbreak for 'Hayward'. The vertical dotted line in the upper graph indicates chilling hours for $95 \%$ of the regression asymptote. Significance of the regression coefficient was determined at $P<0.05$.
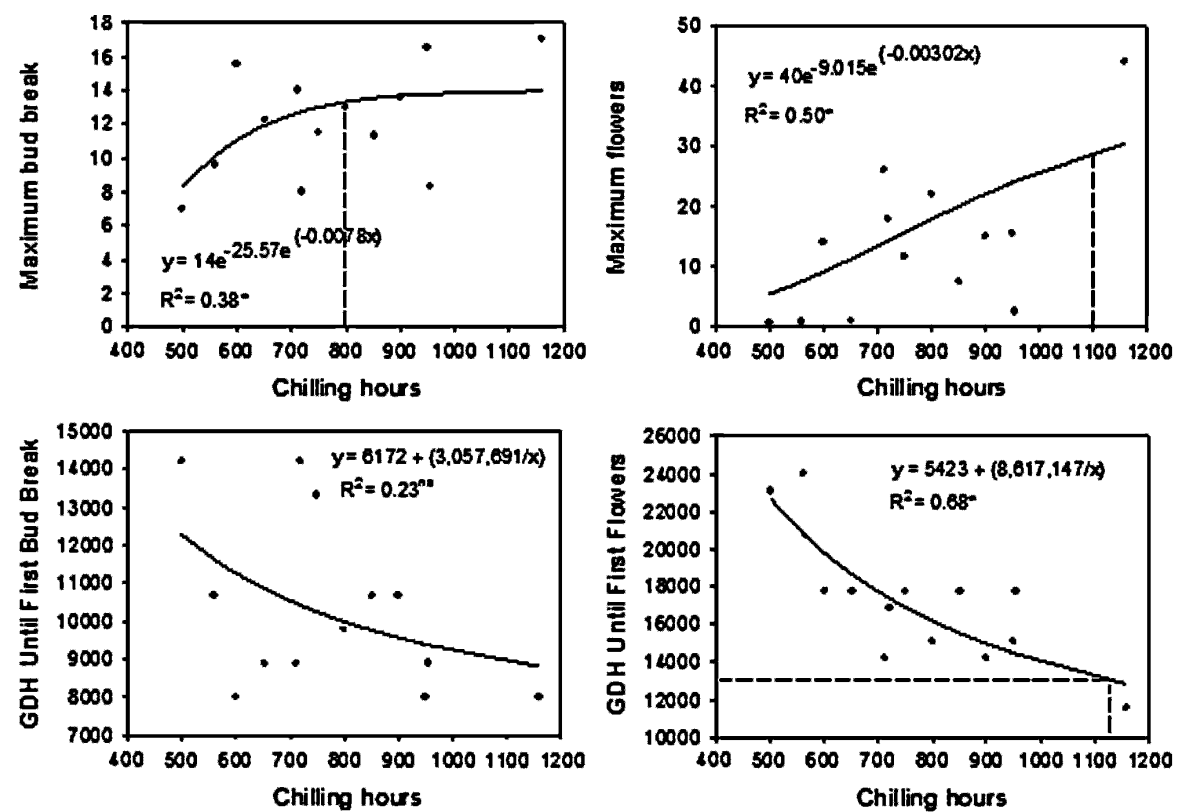

Fig. 4. The effect of chilling hours on maximum budbreak and flowers and the effect of GDH on time until first budbreak and first bloom for 'AU Fitzgerald'. The vertical dotted lines in the upper graphs indicate chilling hours for $95 \%$ of the regression asymptote. The horizontal dotted lines in the lower graphs indicate the number of GDH required to reach first budbreak and first bloom at optimum chilling hours. Significance of the regression coefficient was determined at $P<0.05$.
Mexico where total chilling hours averaged about $600 \mathrm{~h}$. The GDH that required the first buds to break could not be estimated because the regression coefficient was not significant. The number of GDH required for first flowers to show was about $13,000 \mathrm{~h}$

Male A. deliciosa: 'Matua' and 'AU Authur'. Dormant bud rest was completed with $900 \mathrm{~h}$ of chilling for 'Matua' (Fig. 5). The maximum number of flowers that developed did not reach a maximum for this experiment:; nevertheless, the maximum required at least $950 \mathrm{~h}$ of chilling. The GDH required for first buds to break could not be estimated because the correlation of determination was not significant. The GDH required for first flowers to show was about $14,000 \mathrm{~h}$.

Dormant bud rest was completed with $700 \mathrm{~h}$ of chilling for 'AU Authur' (Fig. 6). The maximum number of flowers that developed did not reach a maximum for this experiment; nevertheless, the maximum was estimated to require at least $1000 \mathrm{~h}$ of chilling. The GDH required for first buds to break could not be determined because the correlation coefficient was not significant. The number of GDH required for first flowers to show was at most $11,500 \mathrm{~h}$.

In general, there was much better curve fitting to data, as indicated by higher regression coefficients, for $A$. chinensis than for $A$. deliciosa. No reports were found that determined the chilling requirement for $A$. chinensis. Studies using similar protocols on $A$. deliciosa have had mixed results. Dormant cuttings of $A$. deliciosa 'Hayward' have been reported to grow and produce flowers when placed in water and held at constant temperatures in a greenhouse or growth chamber (Snowball and Smith, 1996). Lionakis and Schwabe (1984) reported that results from use of rootless cuttings were similar to those using intact canes (Snelgar et al., 1997), but Snowball and Smith (1996) reported that cuttings produced more flowers per dormant bud than field-grown plants. The part of the shoot used affects flower and vegetative production (Snowball and Smith, 1996). More flowers tend to develop on cuttings originating from nodes 6 to 20, starting from the base of the original cane, which is the part of the cuttings we used. The same study reported a direct decrease in the number of flowers to reach anthesis as the nodal placement increased. It was proposed by Snowball and Smith (1996) that the reason for the poor performance of cuttings originating from nodes $>20$ to 25 was from insufficient starch reserves. Cuttings originating from nodes 5 and less should be avoided because they may contain no shoot buds and may be less fruitful (Snowball and Considine, 1986).

The size of the cutting was determined to be important when studying flowers (Snowball and Smith, 1996). The amount of starch reserves available has a direct effect on the development of vegetative and floral parts. The same study reported cuttings should be at least $12 \mathrm{~g}$ in weight, at least $150 \mathrm{~mm}$ in length, and $>6 \mathrm{~mm}$ in diameter. The cuttings must be have a constant supply of water. The 

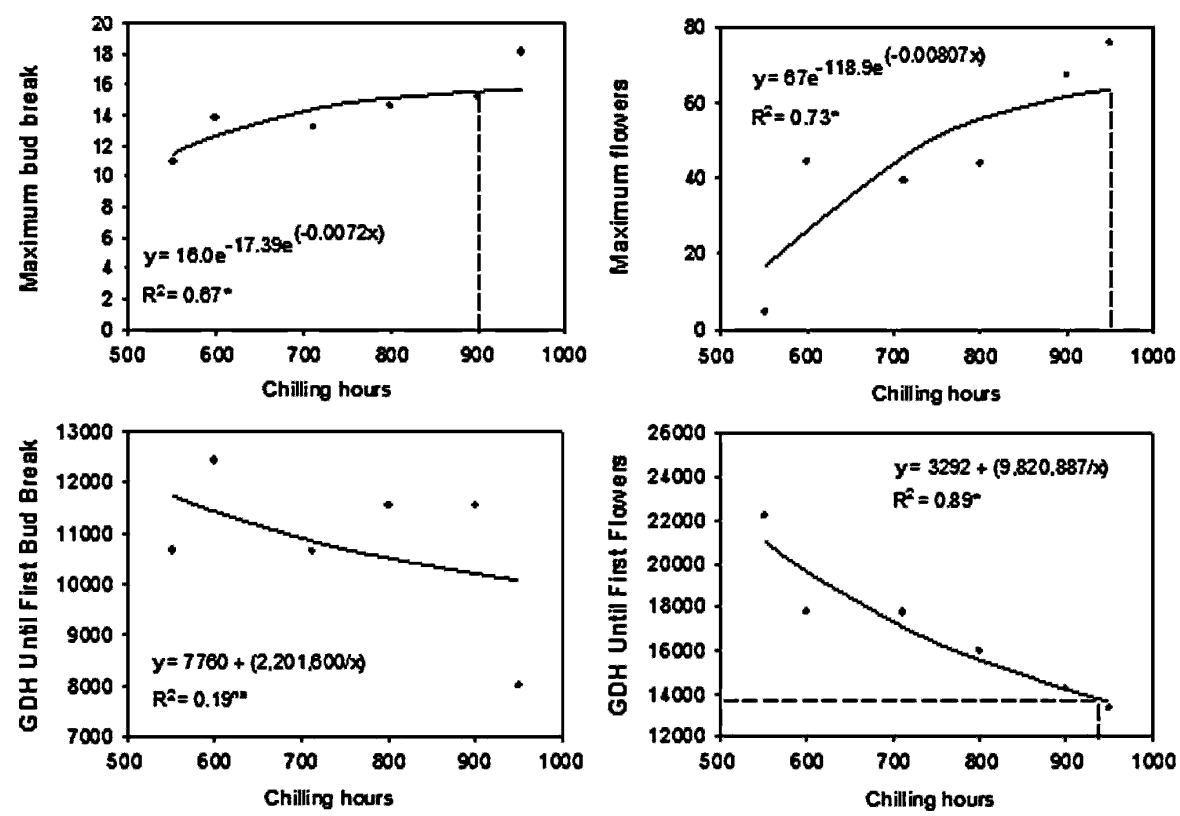

Fig. 5. The effect of chilling hours on maximum budbreak and flowers and the effect of GDH on time until first budbreak and first bloom for 'Matua'. The vertical dotted lines in the upper graphs indicate chilling hours for $95 \%$ of the regression asymptote. The horizontal dotted lines in the lower graphs indicate the number of GDH required to reach first budbreak and first bloom at optimum chilling hours. Significance of the regression coefficient was determined at $P<0.05$.
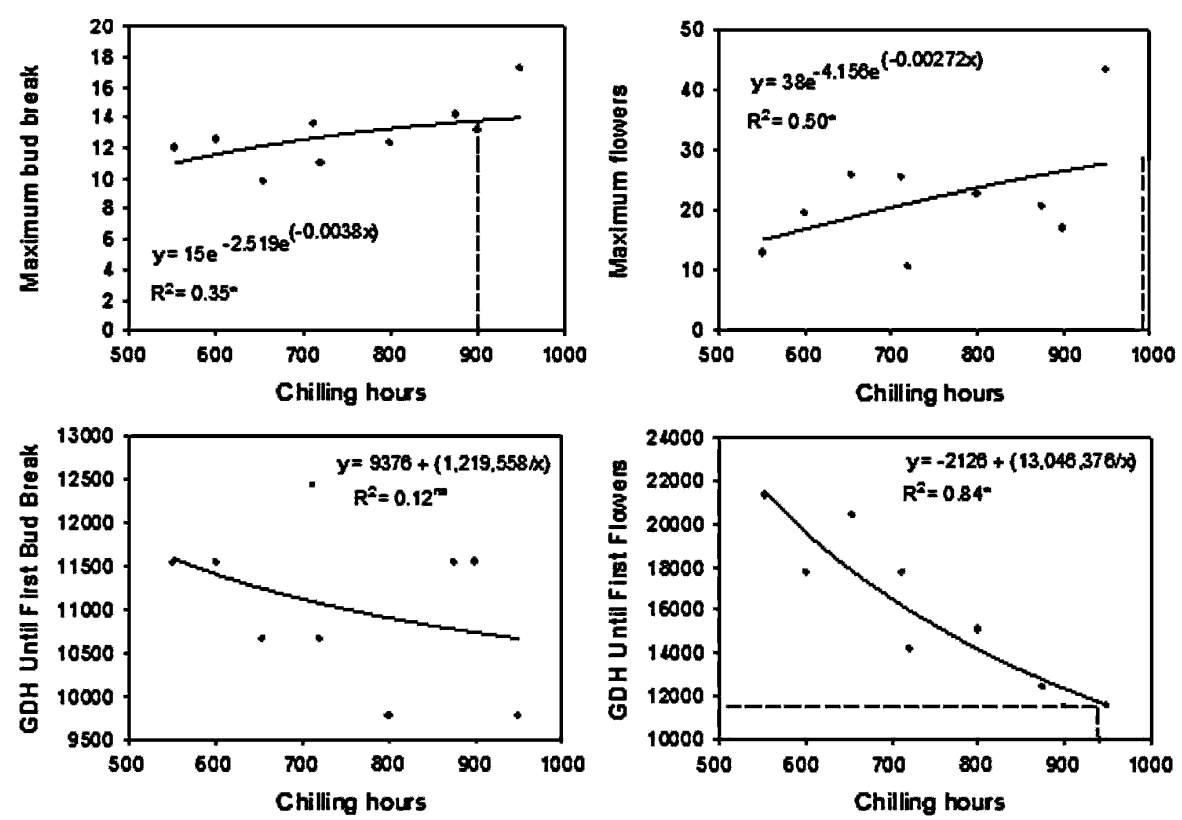

Fig. 6. The effect of chilling hours on maximum budbreak and flowers and the effect of GDH on time until first budbreak and first bloom for 'AU Authur'. The vertical dotted lines in the upper graphs indicate chilling hours for $95 \%$ of the regression asymptote. The horizontal dotted lines in the lower graphs indicate the number of GDH required to reach first budbreak and first bloom at optimum chilling hours. Significance of the regression coefficient was determined at $P<0.05$.

Table 1. Bloom period of kiwifruit cultivars at Chilton Research and Extension Center in Thorsby, AL, 2005.

\begin{tabular}{lr}
\hline Cultivar & Bloom dates \\
\hline Golden Dragon & $4 / 9-4 / 15$ \\
Golden Sunshine & $4 / 29-5 / 10$ \\
Authur & $5 / 12-5 / 16$ \\
Matua & $5 / 9-5 / 12$ \\
Fitzgerald & $5 / 9-5 / 16$ \\
Hayward & $5 / 12-5 / 16$ \\
\hline
\end{tabular}

use of a nutrient solution did not differ from deionized water in promoting budbreak and growth. In the current study, the length of the longest stem was used as an indicator of plant vigor for each treatment. Stem length increased linearly as chilling hours increased for all cultivars (data not shown). 'Golden Dragon' and 'Golden Sunshine' produced the longest stems, at $16.2 \mathrm{~cm}$ and $16.3 \mathrm{~cm}$, respectively.

Bloom of field-grown kiwi Plants of 'Golden Dragon' grown in central Alabama bloomed earlier than the other cultivars included in this study (Table 1). 'Golden Sunshine' bloomed about 2 weeks after 'Golden Dragon'. 'Matua', 'AU Fitzgerald', and 'AU Authur' bloomed about $10 \mathrm{~d}$ after 'Golden Sunshine'. 'Hayward' was the last to bloom.

'Golden Dragon' and 'Golden Sunshine' had the lowest chilling requirements for flowers, at $800 \mathrm{~h}$ and $850 \mathrm{~h}$, respectively. 'Golden Dragon' and 'Golden Sunshine' may be suitable cultivars for more southern regions where chilling hours are typically below 1000 h. 'Golden Dragon' had a lower heat requirement than 'Golden Sunshine', which explains the earlier bloom period for this cultivar in the field. 'Golden Sunshine' may be promising for major production because of its high heat unit requirement of $16,000 \mathrm{GDH}$ for flowering, which would reduce risk to late spring frost.

'AU Fitzgerald' had a chilling requirement of $1100 \mathrm{~h}$ for optimum flower development, and a heat unit of 13,750 GDH. 'AU Authur' may be a suitable pollinator for 'AU Fitzgerald' because of similar chilling requirements, at $1000 \mathrm{~h}$ for both. The amount of heat units required by 'Matua' indicates that it will tend to bloom near the first bloom for 'AU Fitzgerald', making it a good cultivar for covering the first half of the 'AU Fitzgerald' bloom period. 'AU Authur' would be a suitable pollinator for the mid to latter part of 'AU Fitzgerald' bloom season and all of the 'Hayward' season.

\section{Literature Cited}

Caldwell, J. 1989. Kiwifruit performance in South Carolina and effect of winter chilling. Proc. Ala. Fruit and Vegetable Growers Assoc. 10:127-129.

Grant, J.A., V.S. Polito, and K. Ryugo. 1994 Flower and fruit development: An overview. In: Kiwifruit growing and handling. Univ. CA. Div. Agr. Nat. Res., Publication 3344, CA.

Lim, C.C., R. Arora, and E.C. Townsend. 1998 Comparing Gompertz and Richards functions to estimate freezing injury in Rhododendron using electrolyte leakage. J. Amer. Soc. Hort. Sci. 123:246-252.

Lindén, L., P. Palonen, and M. Lindén. 2000. Relating freeze-induced electrolyte leakage measurements to lethal temperature in red raspberry. J. Amer. Soc. Hort. Sci. 125:429435.

Lionakis, S.M. and W.W. Schwabe. 1984. Bud dormancy in the kiwi, Actinidia chinensis Planch. Ann. Bot. (Lond.) 54:467-484.

Samish, R.M. and S. Levee. 1962. The chilling requirements of fruit trees. Natl. Univ. Inst. Agr. 511:372-388.

Snelgar, W.P., P.J. Manson, and H.G. McPherson. 1997. Evaluating winter chilling of kiwifruit using excised canes. J. Hort. Sci. 72(2):305315.

Snowball, A. and J. Considine. 1986. Flowering in kiwifruit (Actinidia deliciosa Liang et Ferguson): Positional effects and development. Acta Hort. 175:85-89.

Snowball, A.M. and R.C. Smith. 1996. Flowering and fruiting rootless cuttings of kiwifruit. N.Z. J. Hort. Sci. 24:355-360.

Thorp, R.W. 1994. Pollination: An overview. In: Kiwifruit growing and handling. Univ. CA. Div. Agr. Nat. Res., Publication 3344, CA. 